\title{
CONVENIENCIA DE LA PARTICIPACIÓN DE LOS NIÑOS EN EL PROCESO DE MEDIACIÓN
}

\section{Appropriateness of children`s involvement in the mediation process.}

Miguel Alarcón Cañuta*

Universidad Católica de Temuco Temuco, Chile

RESUMEN: En este trabajo se estudia la conveniencia, desde el punto de vista jurídico, de la participación de los niños en el proceso de mediación como forma pacífica y menos invasiva de solución de conflictos, y los alcances que, a modo de crítica, tienen las consideraciones que se efectúen para arribar a la conclusión afirmativa o negativa, respecto de la regulación nacional en torno a la institución. Para ello se estima de gran relevancia las apreciaciones y premisas que la doctrina nacional y comparada dan a conocer respecto del interés superior del niño y el derecho a ser escuchado, así como de la mediación, y las notas que la doctrina comparada nos presenta en cuanto a la interrogante principal planteada.

PALABRAS CLAVE: Derecho a ser escuchado, Principio de interés superior del niño, Mediación.

ABSTRACT: In this paper we study the suitability, from a legal point of view, of chlidren's involvement in the mediation process as a form peaceful and less invasive of dispute resolution, and its reach, by way of criticism, have considerations that are made to arrive at affirmative or negative conclusion regarding the national regulation around this institution. For it is highly relevant estimated the considerations and premises that national and comparative doctrine

Magister en Derecho Privado, Universidad de Barcelona, España, Abogado Universidad Católica de Temuco, Chile. Correo electrónico: <maac23@gmail.com>

Artículo recibido el 10 de julio de 2015 y aceptado para publicación el 3 de noviembre de 2015 
disclosed regarding the children's best interests principle and the right to be heard, as well as mediation, and the notes that the comparative doctrine presents us of the main question posed.

KEYWORDS: Right to be heard - Principle of child's best interests - Mediation.

\section{INTRODUCCIÓN}

La mediación familiar se constituye en uno de los mecanismos más útiles y efectivos para la solución de una controversia jurídica evitando los excesivos costos emocionales y monetarios que involucra un procedimiento judicial. Desde esta perspectiva se plantean medios y herramientas para poder hacerla más eficiente en cuanto a los resultados que de la misma se puedan obtener por las parejas que concurren voluntariamente ante la labor del mediador.

Los acuerdos que son tomados por las partes del proceso tienen efectos no solo en cuanto a sus propias vidas, sino que en la vida diaria y, muchas veces, de forma permanente, de los hijos de aquellos.

En este sentido, se plantea la posibilidad de introducir dentro del proceso mismo de mediación familiar la participación de los hijos como una forma de anexar un recursos de eficiencia a la mediación en cuanto a la toma de acuerdos y decisiones por parte de los padres; todo ello desde el punto de vista del respeto y protección al interés superior del niño y el derecho a ser oído.

La pregunta que nos hacemos en este punto por tanto es, si la participación de los niños, niñas y adolescentes (NNA) es o no recomendable para maximizar el resultado positivo del proceso y si nuestra legislación actual, de ser factible esta posibilidad, lo permite dando pleno respeto del principio de interés superior del niño o niña, como eje vertebral en todo ámbito de cuestiones que digan relación con los intereses de los niños y niñas.

A través de este trabajo, trataremos de responder a esta interrogante, primero, analizando el concepto, objetivos e importancia de la mediación familiar, enfatizando en la relación estrecha que existe entre el proceso y los intereses de los NNA en cuanto a los ámbitos en los que las decisiones que tomen las partes impactan la vida de los hijos.

En segundo lugar, desde la base del reconocimiento normativo del derecho de los niños a ser oído, su análisis como tal y sus consecuencias tanto para ellos como para los terceros, determinaremos las consecuencias positivas y negativas de la participación de los NNA en el proceso de mediación. 
Respondida esta pregunta, determinaremos la doctrina existente a favor y en contra de la participación de los niños en el proceso de mediación, conociendo las posturas mayoritarias, planteando la nuestra, para luego analizar críticamente, desde la base de nuestros resultados previos, la normativa existente en nuestra legislación y las posturas doctrinarias contrarias.

Finalmente, a modo de cierre, generaremos algunas conclusiones que nos parecen relevantes para la mejor comprensión y cohesión de las ideas vertidas a lo largo del trabajo.

\section{MEDIACIÓN FAMILIAR E INTERÉS SUPERIOR DEL NIÑO}

\section{Mediación Familiar. Concepto e importancia}

La mediación como forma alternativa de resolución de conflictos tiene una importancia determinante en la relaciones de familia, principalmente atendido la gran cantidad de conflictos, no solo que repercuten en el ámbito jurídico, que se generan tras un proceso de ruptura de la pareja estable o matrimonial, sino con mayor relevancia, por las consecuencias que se derivan de tales rupturas en el ámbito socio afectivo de los miembros del núcleo familiar, y mayor atención, en los niños ${ }^{1}$.

La Ley No 19.968, del 25 de agosto de 2004, que crea los Tribunales de Familia, establece en su artículo 103 que, se entiende por mediación aquel sistema de resolución de conflictos en el que un tercero imparcial, sin poder decisorio, Ilamado mediador, ayuda a las partes a buscar por sí mismas una solución al conflicto y sus efectos, mediante acuerdos.

La mediación familiar se constituye en herramienta importante desde el punto de vista de la solución eficiente de la controversia jurídica ${ }^{2}$, que al mismo tiempo toma en consideración, con mayor grado que otra forma de solución de conflictos jurídicos en el ámbito de la familia, los reales alcances que el proceso de ruptura tiene en todos los integrantes de la familia, integrando una relación más armónica entre bajos costos de transacción, mayor

PAVEZ (2008) p. 186.

2 En este sentido, Pavez (2008) p. 197, citando al State Justice Institute (SJI). Normas recomendadas para los programas anexos de mediación en los tribunales. Traducción al castellano por la Fundación Libra de Argentina, Buenos Aires, 1993. 
satisfacción con el resultado, menores efectos perjudiciales en la relación entre las partes y una menor recurrencia entre los participantes ${ }^{3}$.

Tomando en cuenta lo anterior, se puede conceptualizar someramente la mediación familiar como aquella forma alternativa de resolución de conflictos, distinta a un proceso judicial propiamente tal, que en el ámbito de las relaciones jurídicas del derecho de familia, tiene por objeto extraer las reales pretensiones y/o aspiraciones de las partes en conflicto a través de una serie de actos no contenciosos, no obligatorios pero vinculantes en caso de acuerdo, de manera tal de encontrar conjuntamente y a partir de las experiencias de las propias partes, la solución más benigna y eficiente posible para los miembros del grupo familiar en su totalidad.

Desde esta perspectiva, importante en el proceso de mediación por tanto será la labor del mediador, quien no siendo un juez, se encargará de extraer desde la profundidad del ser de las partes, sus reales sentimientos y pretensiones en cuanto al problema jurídico que se plantea, encontrándose muchas veces con actitudes no colaborativas de parte de los asistentes a las sesiones de mediación, debiendo superar estas barreras con técnicas y estrategias que le permitan hacer aflorar las intenciones de las partes. El logro de lo anterior no solo se tomará como una acción eficiente del mediador, sino que es un requisito sine qua non del proceso mismo, toda vez que la necesidad de encontrar la solución más eficiente y benigna posible para los miembros del grupo familiar requiere primero el conocimiento por parte del mediador de las expectativas de las partes, de tal forma de orientarlas para que ellas mismas sean quienes generen los espacios comunes de solución del conflicto.

Llama la atención en nuestro concepto la referencia que se realiza a la solución más benigna y eficiente posible para los miembros del grupo familiar en su totalidad, lo que tiene su razón de ser.

La solución que el mediador ayuda a encontrar a las partes debe ser aquella que en la mayor medida de lo posible sea la más benigna y eficiente para todos los miembros del grupo familiar, donde no solo los adultos (en relaciones de convivencia de pareja estable o matrimonial) serán los actores principales del proceso, sino que mayor aun, los niños que se encuentren inmersos en ese núcleo familiar, a quienes de forma importante, sea cual fuere

Stella pp. 5 - 9, citando a Ury, William et.al. Cómo resolver disputas - Diseño de sistemas para reducir los costes de conflicto. Traducción al castellano a cargo de Fundación Libra, al cuidado de Elena Highton, Gladys Álvarez y Graciela Tapia, Editorial Rubinzal - Culzoni, Buenos Aires, 1995. 
la decisión, les afectará; todo ello atendido a las especiales condiciones en que se encuentran. Así entonces, la relación que la mediación tiene con las consecuencias que desde el punto de vista de los intereses en juego tienen las partes no solo se traduce en un mecanismo eficiente para encontrar soluciones beneficiosas a los problemas de las partes; sino que más aún, es la herramienta que permitirá encontrar la solución más eficiente y benigna para los integrantes de todo el núcleo familiar y, con mayor medida, acorde a los intereses de los niños y niñas que en aquel se encuentren inmersos.

El respeto del principio del interés superior del niño se traduce especialmente en este ámbito de cuestiones, esto es, encontrar aquella solución que sea en la mayor medida de lo posible, la más eficiente y benigna para sus intereses, pues en definitiva será a estos a los que en mayor medida afectará, o incluso perjudicará, la ruptura de la pareja estable o matrimonial.

Teniendo en cuenta lo señalado, veamos algunas definiciones de la mediación familiar, que toman en cuenta su objeto, de tal forma de hacer algunas apreciaciones.

Según García, tomando en cuenta lo establecido en la Carta Europea de Mediación, podría decirse que la mediación es voluntad de abrir caminos, de establecer lazos, de una forma creativa, allá donde no existe un espacio de comunicación, en el que un tercero, imparcial, independiente y sin poder alguno, suscite constantemente en quienes, encerrados cada uno en su monólogo se encuentran atrapados en el conflicto, el deseo de elaborar conjuntamente una salida, restableciendo un "yo" y un "tú" que permita un verdadero diálogo. Es una estrategia donde dos antagonistas aceptan perder para llegar a ser, ambos, ganadores ${ }^{4}$.

La autora agrega que para SUARES no se debe definir la mediación como la institución para solucionar conflictos, sino la que ayuda a las partes a encontrar otra forma de encarar y conducir sus disputas. Por otro lado, señala que al parecer Villagrasa y Vall Ríus coinciden, en lo esencial, con Suares, ya que el objeto de "facilitar las vías de diálogo" — en palabras de los primeros-, podría identificarse con ayudar a las partes a desempatarse - en palabras de la segunda— de sus posiciones.

La idea de lograr un acuerdo facilitando la comunicación a través de la participación de un proceso guiado por un tercero imparcial, independiente

$4 \quad$ García (2003) pp. 55 y 56. 
a las partes se repite en otros autores, con ciertas diferencias entre ellos, pero conteniendo lo esencial ${ }^{5}$.

En la Ley Catalana № 15/2009, de 22 de junio, sobre mediación en el ámbito del derecho privado se define a la mediación como el procedimiento no jurisdiccional de carácter voluntario y confidencial que se dirige a facilitar la comunicación entre las personas, para que gestionen por ellas mismas una solución a los conflictos que las afectan, con la asistencia de una persona mediadora que actúa de modo imparcial y neutral; como método de gestión de conflictos, pretende evitar la apertura de procesos judiciales de carácter contencioso, poner fin a los ya iniciados o reducir su alcance. En cuanto a los objetivos específicos de la mediación familiar enumera en su artículo 2 varios, de los cuales destacan aquellos relacionados con los conflictos - así lo establece- derivados de la potestad parental y del régimen y forma de custodia de los hijos, conflictos relativos a la comunicación y relación entre progenitores, descendientes, entre otros.

\section{Relación de la Mediación Familiar y el Interés superior del niño}

Teniendo en cuenta lo señalado por los autores especificados y la legislación de aplicación principal en materia de mediación familiar en el ámbito de la comunidad autonómica de Cataluña, se extraña en el concepto y el planteamiento de los objetivos de la misma, la alusión que ya en párrafos anteriores de este acápite hacíamos en torno a la estrecha relación que existe entre los fines de la mediación, como el logro de acuerdos en base a decisiones que sean lo más benignas y eficaces para todo el núcleo familiar, y el interés superior del niño, como aquel estrechamente vinculado y afectado por tal acuerdo de los padres. Se manifiesta en este sentido la consideración entre

En esta línea se han manifestado Bustello (1995) p. 10., donde expresa que: "La mediación familiar interdisciplinaria o compleja es aquella intervención de un equipo multiprofesional representado en la persona del o de los mediadoras/es, no vinculado a las partes de un conflicto familiar de separación o divorcio, matrimonial o no, que lo hace en un principio a solicitud de cualquiera de ellas o de ambas, con el objetivo de promover una forma alternativa, no jurisdiccionalmente contradictoria, de resolución del conflicto familiar originado por la cesación de la vida marital."; Haynes (1995) p 11; Moore (1995) p. 44, lo define como la intervención, en una disputa o negocio, de un tercero aceptado, imparcial y neutral que carece de un poder autorizado de decisión, para ayudar a las partes en una disputa a alcanzar voluntariamente su propio arreglo mutuamente aceptable; Torres (2000): "toda actividad de un tercero neutral, tendente a acercar las posiciones antagónicas de las partes de un conflicto y, eventualmente, a proponer un acuerdo de solución". 
los autores de estimar como partes en el proceso de mediación a los padres, sin atender en los enfoques de la mediación familiar al carácter de interesado que también los niños tienen en el proceso.

Lo anterior, sin embargo, no es la regla general, y algunos autores se han pronunciado en el sentido último mencionado, aumentando el ámbito de eficacia de la mediación familiar al campo, precisamente, de los intereses de la familia en extenso, y no limitada solamente a aquellos intereses de las partes en conflicto. Tal es el caso de García VillaluenGa, para quien el objeto final de la mediación familiar es el logro de la comunicación entre las partes, tratando de plasmar intereses comunes en un acuerdo viable y estable que resulte satisfactorio para ambas partes, y atienda, también a las necesidades del grupo familiar, especialmente las de niños, niñas y personas que padecen algún tipo de discapacidad .

Se aprecia en este autor, en la misma línea en que veníamos argumentando, la necesidad de tomar en cuenta esta estrecha relación entre la mediación familiar, como forma de poner término al conflicto, la familia y - decimos-, el interés superior del niño, atendido a que los acuerdos que las partes protagonicen personalmente, acciones y decisiones, tendrán repercusiones directas en todo el sistema familiar ${ }^{7}$. Importante en este punto es señalar que ya la Recomendación de 1998, Principio III $^{8}$ obliga al mediador a mantener por sobre todo ámbito de cuestiones, incluso siendo el objetivo principal del proceso de mediación, el interés superior del niño.

Es esto lo que, al parecer, toma en cuenta nuestra legislación nacional si leemos el artículo 105 letra e) de la Ley № 19.968 de 2004, donde podríamos señalar que tal norma da cuenta de la consideración de esta relación importante entre los objetivos y fines de la mediación y la consideración del interés superior del niño, al establecer que durante todo el proceso de mediación, el mediador deberá velar porque se cumpla — como principio del procedimiento de mediación - el interés superior del niño, por el cual, en el curso de la mediación, el mediador velará siempre para que se tome en consideración el

\footnotetext{
García (2006) pp. 274 y 275.

CARVo (2008) p. 388
}

$8 \quad$ Establece que: "el mediador tendrá como objeto principal, el bienestar y el interés superior del menor e instigará a los padres a concentrarse en las necesidades del menor y recordará a los padres su responsabilidad primordial, el bienestar de sus hijos y la necesidad que tiene de informarles y consultarles". 
interés superior del niño, niña o adolescente, en su $\operatorname{caso}^{9}$ — volveremos sobre este punto-.

Teniendo en cuenta lo dicho, y situándonos en el conflicto de ruptura de los padres, preciso es determinar el ámbito de aplicación del proceso de mediación, en lo que a nosotros nos interesa, para conocer de forma precisa los impactos que tendrán las decisiones de las partes en cuanto a sus intereses, y principalmente en los intereses de los niños y niñas.

Si bien se pueden encontrar otras manifestaciones de aplicación de la mediación familiar, es en los casos de cuidado personal, relación directa y regular y patria potestad ${ }^{10}$ en que tiene mayor preponderancia para nuestro estudio $^{11}$. En efecto, en todas estas situaciones existen grandes intereses de las partes, que no solo se traducen en sus aspiraciones personales, sino que tienen que ver en gran medida con situaciones que repercuten directamente en la vida de los hijos, como son la determinación de la patria potestad, la guarda y custodia, los alimentos, el régimen de relación directa y regular. Tales instituciones jurídicas tienen un efecto tan importante en la vida de los niños y niñas, pues velan por su desarrollo físico, psicológico y afectivo, que en definitiva son las manifestaciones más patentes que dentro del ámbito de las relaciones familiares tiene el interés del niño ${ }^{12}$. Desde otro punto de vista, y en términos generales, el conflicto familiar, en específico, enferma todo el sistema de la familia; la quiebra matrimonial $-y$ de la unión civil hoy en día - desestabiliza emocionalmente el matrimonio - y a las uniones civiles que conforman la pareja estable-, se transmite a los hijos y arrasa la intimidad del hogar ${ }^{13}$.

Se aprecia por tanto el impacto que sobre la vida de los niños tienen las decisiones que toman los padres en el proceso de mediación, hasta el punto de determinar una situación de hecho que perdurará en el tiempo, muchas veces tornándose permanente.

9 La norma en su redacción completa establece que el mediador deberá velar siempre por el "Interés superior del niño: por el cual, en el curso de la mediación, el mediador velará siempre para que se tome en consideración el interés superior del niño, niña o adolescente, en su caso, pudiendo citarlos solo si su presencia es estrictamente indispensable para el desarrollo de la mediación.".

10 La legislación española habla de delación tutelar, plan de parentalidad y potestad parental.

11 Villagrasa (2011) pp. $106-111$.

12 Sanchez-Eznarriaga (2011) pp. 72 - 76.

13 Garcia (2003) p. 70. 


\section{Modelos de mediación y la consideración de todos los integrantes de la familia}

En este sentido, es muy importante para lo que acabamos de señalar en párrafos anteriores, considerar los modelos de mediación que en la actualidad existen, a fin de entender la consideración que de la misma tiene nuestro ordenamiento jurídico para efectos del estudio que nos convoca.

Siguiendo a la autora SUARES, podemos diferenciar claramente tres modelos de mediación. Por una parte encontramos el modelo de Harvard que centra su atención en la búsqueda y captación de los intereses de las partes, de manera de lograr, a partir de los mismos, la solución a la controversia. Por otro lado, el modelo transformador apunta al cambio o transformación de las ideas que las partes tienen, en una relación de tipo competitiva, sobre sí mismas y sobre la otra, de tal manera de posibilitar el entendimiento, en lo que se denomina una relación cooperativa como facilitadora del acuerdo ${ }^{14}$.

Finalmente, el modelo circular narrativo, que la autora posiciona entre los antes señalados, y siguiendo a MANUERA ${ }^{15}$, encuentra sus fundamentos en la psicología del yo, el paradigma de la comunicación humana, la Teoría General de Sistemas ${ }^{16}$, en conceptos de cibernética y en la causalidad circularidad de las pautas de interacción familiar ${ }^{17}$. Para este modelo importan las relaciones que se generan entre los participantes de un sistema en el cual todos los componentes del mismo se encuentran interrelacionados de manera interdependiente. Con ello en mente, y decantando tales ideas en el proceso de mediación, el resultado del acuerdo necesariamente requiere de la participación de cada uno de los componentes del sistema, esto es, cada uno de los

14 SuARES (2008) pp. $46-47$.

15 Munuera (2007). En su trabajo describe el modelo circular narrativo propuesto por Sara Cobb, "referente teórico del modelo circular narrativo", p. 88.

16 Ibíd., p. 86, expresa que: "La persona se encuentra inserta en un "sistema", siendo los miembros de ese sistema interdependientes. Han sido las contribuciones científicas de autores como Bertalanffy, Haley, Russell, Shannon, Von Neumann, Watzlawick, Wiener [...] las que ayudan en la comprensión de los procesos de comunicación en la familia, El ciclo de vida familiar: roles y reglas, los procesos de cambio...".

17 Id., expresa que: "si bien en las cadenas progresivas lineales de causalidad, tiene sentido hablar acerca del comienzo y el fin de una cadena, tales términos carecen de sentido en los sistemas con circuitos de retroalimentación. En un círculo no hay comienzo ni fin. En el mundo no es posible encontrar el claro y lineal ordenamiento de causa y efecto [como sucede en el modelo lineal o de Harvard], a menos que se lo imponga artificialmente. La teoría general de sistemas considera que la causalidad es un proceso circular". 
integrantes o miembros del núcleo familiar, que como elementos del sistema — familia—, se encuentran interrelacionados de manera interdependiente ${ }^{18}$.

Es precisamente desde esta última perspectiva que podemos comprender lo que a lo largo de los párrafos anteriores veníamos diciendo en torno a la estrecha relación entre los objetivos y fines de la mediación y la consideración del interés superior del niño, desde el punto de vista de la influencia o repercusiones que el acuerdo al que sus padres arriben tendrá en su vida. En efecto, desde el punto de vista de la Teoría General de Sistemas, la familia en la sociedad se circunscribe como un sistema que se interconecta con otros similares —otras familias-, compuesto internamente por elementos interrelacionados. Son los miembros de la familia. Tales miembros de la familia, como en todo sistema, se vinculan unos con otros, lo que significa que cualquier acontecimiento que tenga repercusiones en la vida de uno, necesariamente influirá en la vida del resto. En efecto, se describe la forma de la familia como sistema peculiar de interacciones, donde como entidad social de grupo, toda información acerca de los efectos de la acción de uno cualquiera de los integrantes de la misma, regresa para afectar al sistema mismo ${ }^{19}$, y consecuentemente a otros de sus integrantes.

\section{EL DERECHO DEL NIÑO A SER OÍDO Y SUS CONSECUENCIAS EN LA PARTICIPACIÓN DE NIÑOS Y NIÑAS EN EL PROCESO DE MEDIACIÓN FAMILIAR}

Conociendo la vinculación clara que las decisiones y acuerdos que se toman en el proceso de mediación tienen en relación a los intereses del niño, lo cual a nuestro juicio ya habilitaría para que éste pueda participar activamente en los actos del proceso, es necesario determinar, antes de la respuesta definitiva a nuestro cuestionamiento, si es o no beneficioso para sus propios intereses su participación en la mediación familiar.

\section{El derecho del niño a ser oído}

La Declaración Universal de Derechos del Niño, ratificada por nuestro país, establece en su artículo 12 que "Los Estados Partes garantizarán al niño que esté en condiciones de formarse un juicio propio el derecho de expresar

18 Id., señala que "G. Bateson [citando a Berger, 1993] demostró que todo conocimiento de los acontecimientos externos proviene de las relaciones existentes entre ellos. Se reconoce en el hecho de que, para adquirir una percepción más exacta, un ser humano recurrirá siempre a los cambios en la relación entre él y el objeto externo».

19 Roulz (1989) p. 121. 
su opinión libremente en todos los asuntos que afectan al niño, teniéndose debidamente en cuenta las opiniones del niño, en función de la edad y madurez del niño. 2. Con tal fin, se dará en particular al niño oportunidad de ser escuchado, en todo procedimiento judicial o administrativo que afecte al niño, ya sea directamente o por medio de un representante o de un órgano apropiado, en consonancia con las normas de procedimiento de la ley nacional".

A nivel comparado, la carta fundamental española en su artículo 39 consagra tanto la protección a la familia como a los hijos. En este sentido, la Ley Catalana 11/2010, del 27 de mayo, sobre los derechos y oportunidades en la infancia y adolescencia, en su artículo 7 reglamenta el Derecho a ser "escuchado" en los niños y los adolescentes, de acuerdo con sus capacidades evolutivas y con las competencias alcanzadas, y en cualquier caso, a partir de los doce años, donde deben ser escuchados tanto en el ámbito familiar, escolar y social como en los procedimientos administrativos o judiciales en los que se encuentren directamente implicados y que conduzcan a una decisión que afecte a su entorno personal, familiar, social o patrimonial. Se expresa además que los niños y los adolescentes pueden manifestar su opinión por sí mismos o mediante la persona que designen, y que en el ejercicio del derecho a ser escuchado deben respetarse las condiciones de discreción, intimidad, seguridad, recepción de apoyo, libertad y adecuación de la situación.

Por nuestra parte, la Constitución Política de la República en el artículo 1 consagra la protección a la familia. A su vez, la Ley No 19.968 de 2004 establece el derecho de los niños y niñas a ser escuchados en el procedimiento ordinario, de acuerdo al artículo 69 de la mencionada Ley, pudiendo escucharlos con objeto de tener en cuenta sus opiniones, atendiendo a su edad y madurez. A su vez, el artículo 105 letra e) establece que el mediador podrá citar a los niños, considerado su interés superior, en casos que sea estrictamente indispensable para el desarrollo de la mediación ${ }^{20}$.

El derecho a ser escuchado, consagrado como tal en la Declaración Universal de Derechos del Niño y en el ordenamiento jurídico establece, más que lo señalado en el propio texto de la norma, que el niño deba ser oído en todas aquellas materias que le son de su interés ${ }^{21}$. En efecto, la consa-

20 La norma en comento señala: "Interés superior del niño: por el cual, en el curso de la mediación, el mediador velará siempre para que se tome en consideración el interés superior del niño, niña o adolescente, en su caso, pudiendo citarlos solo si su presencia es estrictamente indispensable para el desarrollo de la mediación".

21 Couso (2006) p. 153, expresa que el derecho a ser oído de la Convención sobre los Derechos del Niño se referiría a cualquier niño que pueda tener algo relevante que comunicar 
gración como obligación de los poderes públicos de "escuchar" importa que deba "oírse" a los niños. Tal aseveración, en la misma línea que VARGas PaVEZ y Correa Camus, tiene un sentido obligatorio directo hacia los entes que gestionan cualquier situación que tenga una estrecha relación con los intereses de niños y niñas, debido a que como ya se planteó, para cada gestión que se realice, y que pueda afectar sus intereses, se debe necesariamente tomar en consideración las pretensiones del propio niño, lo cual no se traducirá solamente en conversar con él para conocer lo que hace, lo que le gusta, las características de su entorno familiar, social, cultural, etc., sino que con mayor relevancia, sus intereses, inquietudes, aprehensiones y pretensiones internas que se relacionan con cualquier situación que genere consecuencias en él, y le afecte.

Tal es la preponderancia del derecho a ser oído, que en estrecha relación con el principio del interés superior del niño, determinan las herramientas básicas con las cuales podrá, y deberá, contar aquella persona que gestione tales procesos; todo ello pues, de acuerdo a lo argumentado por las autoras, el oír al niño o niña importa no solo plasmar en los actos la pretensión principal de la Declaración de los Derechos del Niño, esto es, que sean estimados como sujetos efectivos de derechos, sino que más allá, constituye la forma básica de concretar la participación efectiva ${ }^{22}$ de los niños en los procesos que les afectan desde su propia perspectiva y experiencia ${ }^{23}$.

Teniendo en consideración lo antes expuesto, y de acuerdo con lo señalado por las autoras, aún si ni en la Declaración Universal de Derechos del Niño, ni en la Ley Catalana 15/2009 de 22 de julio, o en la Ley № 19.968 de 2004 se establece, el derecho a ser oído se configura como un derecho de participación del niño en la esfera de cuestiones que le afectan. En este sentido, la Observación General № 12 de 2009, del Comité de Derechos del Niño (Comité), en torno al derecho del niño a ser escuchado, estableciendo que tal derecho se constituye en uno de los valores fundamentales de la Convención de Derechos del $\mathrm{Niño}^{24}$, señala expresamente "[...] que se trata de una participación que no se agota en una o dos actuaciones concretas, sino que debe entenderse como un proceso con permanencia en el tiempo." ${ }^{\prime 25}$.

sobre un asunto que le afectará.

22 Ibíd. p. 148.

23 Vargas y CoRrea (2011) p. 180.

24 Comité de los Derechos del Niño (2009) p. 5.

25 Ibíd. 
De esta forma, conociendo la relevancia determinante que ostenta el derecho a ser oído, en estricta concordancia con el principio del interés superior, y la relevancia que el proceso de mediación determina sobre los propios intereses del niño, como se argumentaba en el acápite anterior, vemos la necesidad de la participación de los niños y niñas en el proceso de mediación, toda vez que no solo como derecho, sino que como obligación hacia los poderes públicos, opera como garante de la participación que ellos deben tener en los procesos que le afectan, atendidos los alcances que sobre la vida futura, a largo plazo, ostentan las decisiones que los padres tomarán a la hora de la ruptura de la pareja estable o matrimonial.

Lo anterior no es de poca importancia si tenemos en cuenta que la totalidad de las formas de participación de los niños en los procesos de familia se lleva a cabo en el ámbito judicial, ya sea como testigo, como sujeto de peritaje o en una audiencia especial al efecto. En tales circunstancias se puede cuestionar el respeto del mandato de participación efectiva de los niños en aquellas materias que le son de su interés, toda vez que en circunstancias como las señaladas, se coincide por la psicología que son factores estresores de alto grado para el desarrollo normal de las habilidades y capacidades de niños y niñas. En este sentido, se ha establecido que: "La asistencia del menor a una exploración psicológica forense, donde se va a evaluar su credibilidad y la presencia en una sala de visitas para declarar ante personas nuevas y desconocidas son situaciones que generan una respuesta de estrés muy importante en el niño.

Mira y Diges (1991): las condiciones de amenaza y estrés limitan la capacidad para fijarse y atender a los detalles; recordad ciertos aspectos esenciales de la situación;

Chrisianson (1992): el estrés actúa sobre la memoria de testigos en función de: el tipo de suceso, emocional o neutro, el tipo de detalles que se han de recordad, periféricos o esenciales dentro de un contexto emocional, la demora en la toma de declaración, las condiciones del recuerdo, estado de ánimo, ayudas, claves contextuales, etc ${ }^{\prime \prime 2}$.

Ante esto, por tanto, la participación de los niños en un ambiente muy distinto al de un proceso judicial propiamente tal, se considera permitiría la proliferación voluntaria de sus capacidades de comunicación, no solo verbal,

26 Universidad de Alicante, Licenciatura en Criminología, Asignatura: Psicología Criminal, "El menor como testigo". 
sino que, y de mayor importancia, gestual ${ }^{27}$; donde la labor del mediador será por tanto, la de oír al niño, poniendo atención a sus palabras, gestos, acciones, los cuales darán a conocer sus experiencias y pretensiones respecto a los acontecimientos ${ }^{28}$. En este sentido, se considera además, y existen evidencias, que introducirlos en el proceso conlleva explicar la situación y reducir sus preocupaciones, y que su participación repercute positivamente en su autoestima y funcionamiento psicológico, ayuda a desarrollar la capacidad de la autosuficiencia, siendo más fácil al niño salir de la dependencia familiar, y facilita la adaptación a la nueva situación tras haber recibido una explicación ${ }^{29}$.

\section{Capacidad de los niños para participar en el proceso de mediación familiar}

La participación de los niños y niñas en el proceso de mediación familiar, como vemos hasta ahora, es necesaria, pero debemos analizar si es beneficiosa para sus intereses.

La necesidad de la participación de los niños, como veíamos, se condice con lo señalado por SÁnCHEZ-EZnARRIAGA, quien señala que "la proliferación de procesos familiares en los que de una u otra forma se ven involucrados menores, así como la evolución social y legal, que se ha venido produciendo en la consideración de estos menores, induce a una reflexión en torno a su situación y la forma en que debe aplicarse el principio de protección que los mismos demandan" ${ }^{30}$.

Tales apreciaciones tienen importancia desde el punto de vista de la capacidad de los niños para poder participar del proceso de mediación, donde hoy en día pareciere ser un problema de difícil valoración y consenso.

27 Couso (2006) p. 153, menciona que lo que tenga que expresar el niño podrá hacerlo incluso a través de formas no verbales. Expresa que la fórmula usada, por ejemplo, por la Children's Act inglesa de 1989 se refiere "no solo a deseos formulados en forma discursiva, sino también a sentimientos expresados de otra forma, lo que es muy relevante para niños con menores competencias lingüísticas o niños que en ciertas circunstancias no pueden verbalizar, pero sí demuestran de formas perceptibles (a veces, con vehemencia) sus sentimientos positivos o negativos frente a ciertas opciones".

28 VARGAS y CORREa (2011) p. 184.

29 Valero (2010) p. 92.

30 Sánchez-Eznarriaga (2011) p. 59. 
Tomando las palabras de VAlero MATAS, en cuanto a la fijación de edad mínima para que un niño pueda participar en un proceso de mediación, la normativa reguladora de la posibilidad de escuchar a los niños en determinados asuntos que se expresan en el Código Civil español sería un mero trámite de exposición de normas, toda vez que estaría restringiendo dar voz a los niños y niñas, en vez de promover el ejercicio sin limitaciones. Lo anterior - expresa - se ve reafirmado en Sentencia del Tribunal Constitucional, STC 163/2009, del 29 de junio, en la que tomándose en consideración el artículo 92 apartado 6 del Código Civil ${ }^{31}$ español, en relación al artículo 9 de la Ley Orgánica 1/1996 del 15 de enero ${ }^{32}$, se interpretaba que los "[...] órganos judiciales deducen que la audiencia al menor no se concibe ya con carácter esencial, siendo así que el conocimiento del parecer del menor puede sustanciarse a través de determinadas personas (art. 9 de la Ley Orgánica 1/1996) y solo resultará obligado cuando se estime necesario de oficio o a petición del Fiscal, partes o miembros del equipo técnico judicial, o del propio menor (art. 92.6 CC). Esta argumentación no puede entenderse que incurra en irrazonabilidad, error patente o arbitrariedad, únicas circunstancias que determinarían la lesión del derecho fundamental a la tutela judicial efectiva (art. 24.1 CE) ${ }^{\prime \prime 3}$. De acuerdo a ello, el autor señala que no existiría una obligación por parte de los jueces en España de oír a los niños en aquellos casos en que deba fijarse ciertas condiciones posteriores al divorcio o separación de sus padres —en este caso la guarda y custodia_, por lo que — peor aún-malamente podría esgrimirse una lesión de su derecho fundamental ${ }^{34}$.

31 La norma establece, aún en la actualidad, que "en todo caso, antes de acordar el régimen de guarda y custodia, el Juez deberá recabar informe del Ministerio Fiscal, y oír a los menores que tengan suficiente juicio cuando se estime necesario de oficio o a petición del Fiscal, partes o miembros del Equipo Técnico Judicial, o del propio menor, valorar las alegaciones de las partes vertidas en la comparecencia y la prueba practicada en ella, y la relación que los padres mantengan entre sí y con sus hijos para determinar su idoneidad con el régimen de guarda".

32 STC 163/2009, fundamento jurídico cuarto, segundo párrafo, se establece que "el apartado 2 de este artículo establece que el menor puede ejercitar este derecho 'por sí mismo o a través de la persona que designe para que le represente, cuando tenga suficiente juicio' y que "cuando ello no sea posible o no convenga al interés del menor, podrá conocerse su opinión por medio de sus representantes legales, siempre que no sean parte interesada ni tengan intereses contrapuestos a los del menor, o a través de otras personas que por su profesión o relación de especial confianza con él puedan transmitirla objetivamente".

33 STC 163/2009, fundamento jurídico quinto, párrafo segundo.

$34 \quad$ VALero (2010) p. 97. 
En la actualidad existen múltiples normas relativas a la capacidad de los niños en relación a otras materias, que a simple vista parecieren algunas ser de mayor relevancia en cuanto impactos sobre sus propias vidas. En todas estas materias no se exige la mayoría de edad. Por otro lado, ya sabemos que con la ratificación de la Declaración de Derechos del Niños por los Estados miembros, se concretiza la labor de considerar a los niños como sujetos de derecho, pudiendo ejercitarlos por él o ella.

En ese sentido, y a modo de ejemplo, que la ley Catalana fije como límite de edad los 12 para el ejercicio del derecho a ser oído, impondría una limitación por motivos de edad al ejercicio efectivo por parte de los niños de su derecho a ser oídos, y consecuencialmente, a participar en los procesos de su interés.

Sin embargo, a nuestro modo de ver, independiente del fallo del Tribunal Constitucional ya citado, que el mismo VALERO considera no generar jurisprudencia $^{35}$, y siendo más optimistas, nos atrevemos a decir que de la normativa en estudio no parecer ser la regla general la fijación de una edad mínima para que los niños puedan ejercitar su derecho a ser oído.

En efecto, la redacción del artículo 7 de la Ley Catalana deja la puerta abierta a situaciones en que el niño tenga la madurez suficiente para poder ejercitar su derecho a ser oído a una edad inferior a los 12 años, lo cual a la luz de los estudios de psicología infantil pareciere ser la regla general, y no la excepción. A su vez, la redacción actual de la Ley Orgánica 1/1996 del 15 de enero, en su artículo 9, modificado por la Ley Orgánica 8/2015, del 22 de julio, de modificación del sistema de protección a la infancia y a la adolescencia, pareciera tener una redacción abierta, donde, a pesar de hacer una referencia a la edad de 12 años, alude de forma principal al concepto de madurez, el cual será considerado de acuerdo al desarrollo evolutivo del niño y su capacidad para comprender y evaluar el asunto concreto a tratar en cada caso.

En tal sentido, se ha considerado que los niños comienzan su aprendizaje y percepción de su entorno desde el momento de su nacimiento con cada experiencia vivencial, no al llegar una determinada edad ${ }^{36}$. La misma

35 Ibíd., señala que: "Si a esto [a la modificación del artículo 9.2 del Código Civil español, que restringiría aún más la voz de los menores] le adicionamos, aunque no genera jurisprudencia, la Sentencia del Tribunal Constitucional, (STC) de 29 de junio de 2009 [...] se entorpece aún más, escuchar a los menores ante una ruptura familiar.".

36 Se puede inferir de los estudios realizados por Papalia y Wendoos (1978). 
Observación General № 12 de 2009 del Comité establece que el artículo 12 de la Convención de Derechos del Niños no impone ningún límite de edad al derecho del niño a expresar su opinión, y desaconseja a los Estados partes que introduzcan por ley o en la práctica límites de edad que restrinjan el derecho del niño a ser escuchado en todos los asuntos que lo afectan. El Comité manifiesta que los Estados partes no pueden partir de la premisa de que un niño es incapaz de expresar sus propias opiniones, sino que al contrario, deben dar por supuesto que el niño tiene capacidad para formarse sus propias opiniones y reconocer que tiene derecho a expresarlas. Para ello establece además que "hay estudios que demuestran que el niño es capaz de formarse opiniones desde muy temprana edad, incluso cuando todavía no puede expresarlas verbalmente ${ }^{37}$. Por consiguiente, la plena aplicación del artículo 12 exige el reconocimiento y respeto de las formas no verbales de comunicación, como el juego, la expresión corporal y facial y el dibujo y la pintura, mediante las cuales los niños muy pequeños demuestran capacidad de comprender, elegir y tener preferencias" ${ }^{\prime \prime 3}$.

Pues bien, pareciera ser que nuestra legislación apunta en el sentido antes indicado, toda vez que no dispone un límite específico de edad para posibilitar la participación de los niños en los procedimientos judiciales y la mediación. Ante esto, la doctrina ha señalado que establecer un límite de edad específico para permitir la participación del niño en un procedimiento determinado es perjudicial, no solo en cuanto establecimiento de una limitación al ejercicio de los derechos del niño — que en ciertos casos pudiere ser justificado-, sino que más aún, porque tal limitación en muchos casos podría tornarse en arbitraria ${ }^{39}$.

Teniendo nosotros en cuenta que el derecho del niño a ser oído es una manifestación patente de derechos fundamentales como el de opinión, libertad de expresión y pensamiento, ALAEZ, en base al reconocimiento de la capacidad de obrar iusfundamental para el ejercicio autónomo de ciertos derechos fundamentales que solo pueden ser ejercidos personalmente, establece como criterio preponderante el grado de madurez del niño que se adquiere de forma progresiva, en lo que él denomina la gradual autonomía

37 En este punto cita a LANSDOwn (2005): "The evolving capacities of the child", Centro de Investigaciones Innocenti, UNICEF/Save the Children, Florencia.

38 Comité de los Derechos del Niño (2009) p. 9.

39 En este sentido VARGAS et al. (2010) p. 10, señala que no es pacífico el tema, pero considera riesgoso establecer un parámetro de edad por la "rigidización en la aplicación de los mismos, sin considerar que los niños tienen experiencias de vida y formas de expresarse distintas". 
volitiva del menor ${ }^{40}$. En este sentido, el Comité establece que la madurez de un niño se refiere a la capacidad de comprender y evaluar las consecuencias de un asunto determinado y de expresar sus opiniones sobre las cuestiones de forma razonable e independiente; ello teniendo en cuenta que los niveles de comprensión de los niños no van ligados de manera uniforme a su edad biológica, habiéndose demostrado que la información, la experiencia, el entorno, las expectativas sociales y culturales y el nivel de apoyo contribuyen al desarrollo de la capacidad del niño para formarse una opinión. Termina estableciendo que, por tal motivo, es que las opiniones del niño tienen que evaluarse mediante un examen caso por $\mathrm{CasO}^{41}$.

Con tal apreciación, las experiencias vivenciales que se generan en un contexto de ruptura de pareja estable o matrimonial, no necesariamente deberían ser absorbidas por el niño a una determinada edad, sino que a medida que transcurren, teniendo él sentimientos de apego hacia un progenitor, opiniones específicas con respecto a un tema que le interesa, entre otros. Todo lo cual se debe contextualizar a medida que transcurre su desarrollo, dependiendo de las situaciones que se generen en el caso particular.

De tal forma que la exigencia de una edad mínima en la cual se admita el ejercicio del derecho a ser oído no debiere configurarse en la regla general, tal como lo ha señalado la Suprema Corte de Justicia de la Provincia de Buenos Aires, Argentina, en donde se ha establecido en "reiteradas oportunidades $[. .$.$] que la trascendencia de la decisión sobre el destino del niño$ exige que quien vaya a resolver lo conozca, no importando la edad, sino que '....sea cual fuere su edad, será indispensable verlo, porque ese constituye el verdadero y único modo de saber de él, más allá de los certificados, informes y constancias foliadas; para ser protegido el niño necesita la mirada del juez...'"142, lo cual pareciere estar apuntando ni siquiera a la necesidad de madurez por parte del niño para que ejercite su derecho a ser oído, sino que

Alaez (2003) pp. 152, 153 y 154. Expresa que “¿cuándo adquiere el individuo la suficiente autonomía volitiva como para que predomine su autoprotección y quede relegada su heteroprotección?[...] lo cierto es que el de la madurez es el criterio que mejor pareciere adaptarse a su gradual y evolutiva adquisición de autonomía volitiva", más adelante afirma que "exigir al menor una capacidad de decidir conforme a criterios propios del mayor de edad equivale a negarle la capacidad de autoprotegerse y a considerar que la titularidad y el ejercicio de los derechos fundamentales corresponde, en último extremo a mayores de edad o menores que sean capaces de actuar como mayores.".

41 Comité de los Derechos del Niño (2009) p. 11.

42 Es lo expresado por Figueredo en documento sin fecha publicado en la sección de publicaciones jurídicas de la página web del Poder Judicial de la Provincia de Corrientes. 
por la sola condición de serlo, a quien le afecta una situación determinada, y quien debe poder ser oído por quien tiene las riendas de un proceso (judicial o extrajudicial) que conlleve consecuencias sobre su persona.

De todas formas, tal como lo señala SÁnchez-EZnARRIAGA, siempre que se contempla el criterio de la edad de los niños, o bien el de la madurez, necesariamente deberemos oír al niño, constituyéndose esto en una petición de principio ${ }^{43}$. Termina el autor dando a conocer, a nuestro modo de ver, la necesidad de incorporar este criterio de la madurez de los niños en cuanto a la participación que él mismo pudiese tener en aquellas materias que le son de su interés, sin atenderse solo a la estrictez de la normativa o al solo criterio sesgado del juzgador; expresa que "la existencia de esa posibilidad ampliatoria permite corregir casos en que la aplicación exclusiva y rigurosa de la edad, dejaría sin ser oídos a menores que lo merecen" ${ }^{\prime 4}$.

A todo lo anterior debe además agregarse que el niño, desde que posee derechos fundamentales — tal como ya lo señalábamos-, y siguiendo a CilLero, tiene la capacidad de ejercerlos de forma autónoma, o no ejercerlos, correspondiéndole a él tal decisión; toda vez que con la Convención de Derechos del Niño se reafirma la consideración de sujeto de derecho que se desprende de su carácter de ser persona humana ${ }^{45}$. En este sentido, la autonomía progresiva del niño importa que pueda ejercer su derechos ${ }^{46}$, y en lo que nos convoca, el derecho a ser oído. Y es que la autonomía progresiva se encuentra en estrecha relación con el interés superior del niño, más si tomamos en consideración que en términos prácticos, éste último se traduce, se puede conceptualizar, como el legítimo ejercicio de sus derechos ${ }^{47}$.

Hace alusión, a modo de ejemplo, a la Sentencia de la Suprema Corte de Justicia de la Provincia de Buenos Aires Ac. 78.728, 02 de mayo de 2002.

43 Sanchez-Eznarriaga (2011) p. 65, expresa que: "en las cada vez más numerosas acciones en que se contempla el criterio, preciso, exacto y seguro, de la edad, con otro indeterminado y relativo, referido al suficiente juicio o madurez del menor, además de la incertidumbre en su aplicación, hay que destacar que su expresión contiene en sí misma una petición de principio. Si para darle intervención o ser oído el menor, hay que dilucidar si tiene suficiente juicio, no puede adoptarse esta decisión, sin una valoración personal del menor, esto es, sin oírle personalmente".

44 Ibíd.

45 Cillero (1990) pp. 4 - 5.

46 Couso (2006) p. 150.

47 Cillero (1999), p. 134. 
Lo anteriormente expuesto determina que la participación directa del niño en los procesos de su interés sea la regla general, así como que la participación a través de un representante se deje como último recurso en aquellos casos en los que de ninguna forma el niño pueda expresar por sí mismo, de forma verbal y física, sus pretensiones.

Sentado lo anterior, se debe reiterar la gran importancia que tendrá entonces la labor del mediador, en cuanto persona que deberá "oír" al niño, debiendo crear el espacio para que el mismo se sienta con libertad de exponer sus experiencias, opiniones, gestos, pretensiones. Oyéndolo, el mediador deberá extraer aquellas apreciaciones que sean determinantes, discriminar aquellas situaciones que no tienen relación con el caso, en aptitud receptiva.

Desde nuestro punto de vista, por tanto, más que la posibilidad y necesidad de que el niño participe activamente en procesos de mediación genera múltiples ventajas: la primera y más obvia, el respeto efectivo de su derecho a ejercitar su derecho a ser oído, desde que el mismo engloba la posibilidad de participación efectiva del niño en los procesos que tienen consecuencias sobre su persona, en cumplimiento con el principio de autonomía progresiva. En segundo lugar, y atendida la importancia de los procesos de mediación, y el fomento que los mismos han tenido desde varios años en los distintos ordenamientos jurídicos, la participación de los niños permite que el mediador amplíe el campo de acción en relación a las partes en conflicto, lo que le permite hacerse de información objetiva de primera fuente, no solo en cuanto al problema subyacente entre las partes, sino también en relación a la información que será relevante tomar en cuenta a la hora de orientar a las partes en vista de obtener soluciones que afectarán directamente al niño o niña. En este sentido, tales consideraciones son esenciales para que el mediador logre valorar la posibilidad de que el niño tiene para influir positivamente en el acuerdo $^{48}$. En tercer término, la participación activa del niño en el proceso de mediación permitirá que los padres, atendidos los conceptos analizados de la institución, puedan por sí mismos fomentar la comunicación entre ellos y para con los hijos, de forma tal que las decisiones y acuerdos que tomen,

48 Díaz p. 7, expresa que: "aunque tales consideraciones puedan parecer ajenas a la mediación, no lo son, pues todas apuntan a la necesaria consideración previa por el agente mediador, por un lado, de las posibilidades reales de sometimiento del menor al proceso mediador, y, de otro, de la verosimilitud, consistencia y no condicionamiento de la voluntariedad del sometimiento del menor al referido proceso, así como de la real comprensión por el mismo, tanto de su contenido como de sus objetivos, esto es, la valoración de lo que podría denominarse capacidad natural, entendida como posibilidad real de toma de decisiones plenamente consentidas, válidas, y no condicionadas". 
tengan el valor agregado de surgir desde su valoración, con implicancia directa de los hijos, que hará más eficiente y posible de cumplir el acuerdo.

\section{ANÁLISIS CRÍTICO A LA LUZ DE LA DOCTRINA EN CUANTO A LA PARTICIPACIÓN DE LOS NIÑOS EN EL PROCESO DE MEDIACIÓN FAMI- LIAR}

\section{Doctrina en torno a la participación de los niños en el proceso de me- diación}

Dentro de la doctrina encontramos autores que se postulan a favor de la participación de los niños y niñas en los procesos de mediación, donde se aduce que es parte de la función del mediador educar a los padres e incluso actuar como defensores de las necesidades e intereses de los niños.

En este sentido, Vargas Pavez ${ }^{49}$ defiende la participación de los niños en el proceso de mediación, donde en caso de adolescentes debiera ser la regla general. En su mismo trabajo, señala que EduARdo José CÁrdenAs ${ }^{50}$ sostiene que la incorporación de los hijos en la mediación debe respetar e inclusive reforzar el objetivo de la mediación familiar, que es poner a los padres en situación de conducir acordadamente la familia, en el momento de la separación de la pareja ${ }^{51}$. Se aprecia que en la línea de las argumentaciones del acápite anterior, el autor señala entre las ventajas que tiene la inclusión de los niños en un proceso de mediación "[...]el hecho que esta participación cumple con el mandato constitucional de informar a los niños y escuchar su opinión cada vez que se trata un asunto que lo concierne[...] [y] agrega otros beneficios congruentes con los postulados de la teoría de la mediación, como por ejemplo, que dicha participación permite visualizar las necesidades de los hijos y también con los postulados del enfoque sistémico de la familia en el sentido que "permite completar el circuito del sistema familiar" 52 .

Por su parte SuAREz estima que la inclusión "[...]genera un espacio de confianza en que los niños pueden expresar todos sus sentimientos, dudas, confusiones y que los padres conozcan luego esa información y tomarla en cuenta al momento de decidir" ${ }^{\prime \prime}$.

\footnotetext{
$49 \quad$ VARGAS (2002) pp. 164 y siguientes.

50 Quien se desempeñó por muchos años como Juez de Familia en Argentina.

$51 \quad$ VARGAS (2002) p. 147.

52 Ibíd.

53 SuArez (2003) pp. 389 a 404.
} 
En este mismo orden, en el trabajo de Vargas Pavez se expresa además que "[...] las mediadoras argentinas Carolina Gianella y Sara Curi sostienen que habría dos objetivos básicos en la inclusión de los niños en el proceso de mediación: (a) la participación debe ayudar a potencia los recursos de los padres para la toma de decisiones y (b) la participación debe realizarse dentro de un encuadre capaz de evitar intervenciones iatrógenas, es decir, que no obstaculice el desarrollo de las funciones parentales en forma adecuada" ${ }^{\prime 24}$.

Por otro lado, PARKINSON ${ }^{55}$, condicionando la participación de los niños en el proceso de mediación a requisitos relativos a su protección, señala una serie de ventajas que tendría la inclusión de aquellos, entre las cuales se destacan ayudar a los padres a centrarse en los niños y desterrar los mitos, como sería el caso de que un niño no quiere ver a uno de los padres, cuando en realidad al niño le encanta verlo, además de proporcionar a los padres la información que les ayude a comprender las preocupaciones y sentimientos de niño, a fin de que puedan tenerlas en cuenta a la hora de tomar una decisión.

En esta línea de pensamiento, CARvo argumenta que los niños deben participar en el proceso de mediación en casos muy concretos, cumpliéndose una serie de requisitos, como son el acuerdo de los padres y su compromiso de no aleccionar a los niños una vez terminada la sesión, que se deje en claro al niño que no tiene responsabilidad en la decisión de los padres, que consultas a los hijos se realicen con especial cuidado y sensibilidad, que el mediador cuente con información complementaria así como con habilidades especiales y experiencia en la comunicación con niños y, en caso de no tenerla, que participen en el proceso profesionales experimentados en el trabajo con niños, como fueren psicólogos u orientadores infantiles. ${ }^{56}$

Finalmente, Contreras ${ }^{57}$, antes de la entrada en vigencia de la ley $\mathrm{N}^{\circ}$ 19.968 de 2004, establece la necesidad de que los niños y niñas tengan participación activa en los procesos de mediación de manera tal de, siguiendo a Cillero, respetar el interés superior del niño en su vertiente de considerarlos sujetos de derecho. En este sentido, ya en esa época, cuando la Ley recién señalada estaba en pañales, el autor hace las prevenciones de no entender a los niños y niñas como objetos de protección con la regulación.

\footnotetext{
VARGAS (2002) p. 147.

PARKINSON (2005) pp. 201 - 204.

Carvo (2008) p. 409.

Contreras (2002).
} 
Desde la vertiente contraria, y siguiendo en este aspecto el trabajo realizado por CARVO, los autores que estiman la no participación de los niños en el proceso de mediación en síntesis señalan que minaría la autoridad y poder de decisión de los padres y que influiría en la neutralidad e imparcialidad del mediador; que la presencia de los hijos puede constituir un elemento perturbador por cuanto estos nada tienen que ver con los problemas de los padres, que no han intervenido en su gestación y no tienen recursos para solucionarlos, por lo que no deben conocer las divergencias y detalles íntimos que inevitablemente saldrán a la luz en las sesiones de mediación; cuando existen desacuerdos entre los padres respecto a lo que es mejor para los hijos, llamarles a mediación no es la mejor solución pues ellos necesitan que sus padres, como adultos que son, sepan lo que es mejor para ellos ${ }^{58}$.

\section{Análisis crítico en cuanto a la regulación nacional}

Teniendo como base lo expuesto, tanto desde el lado de los autores que se manifiestan a favor y en contra de la participación de los menores en el proceso de mediación, así como lo argumentado a lo largo de este trabajo, es preciso hacer algunos comentarios críticos.

Partamos señalando que la regulación de la Ley No 19.968 de 2004 nacional, en su artículo 105 letra e), a primera vista pareciera ser coincidente con el respeto del principio del interés superior del niño toda vez que establece un mandato al mediador de considerar tal interés superior en los procesos de mediación, y además, estaría posibilitando que los niños puedan participar en el mismo.

Sin embargo, teniendo en cuenta lo que hemos señalado a lo largo de este trabajo, del análisis profundo de la mencionada norma se puede establecer que la consideración que el legislador tiene del proceso de mediación se basa en el modelo lineal o de Harvard, basado en los intereses de las partes, sin consideración de la dimensión relacional de la familia - tal como lo expresábamos al tratar la doctrina de Sara Cobb-. En efecto, a pesar de que la norma hace alusión al interés superior del niño, se aprecia de la misma que son los intereses de los padres los que serán considerados con preponderancia para el acuerdo, en circunstancias que el niño solo en casos muy excepcionales podrá participar de manera autónoma en el proceso de mediación dando a conocer su punto de vista, sus intereses, su historia. 
A nuestro modo de ver, tal norma confunde el entendimiento del interés superior del niño con el solo interés que es preciso considerar-desde la concepción de Harvard- para arribar a un acuerdo. Pero sucede que, tal como ya hemos tenido oportunidad de señalar, el interés superior del niño tiene estrecha vinculación con la autonomía progresiva del niño, en cuanto facultad de ejercer por sí mismo los derechos que le son conferidos, atendido el carácter de sujeto de derecho que le reconoce la Convención sobre Derechos del Niño.

Desde tal punto de vista, nuestra regulación tiene como regla general que el niño no pueda participar activamente en el proceso de mediación, siendo el mediador el que en definitiva velará por sus intereses, esto es, los defina teniendo en cuenta sus percepciones y experiencias personales. La misma norma establece que solo en casos excepcionales el niño podrá participar en el proceso, y que tal participación requerirá una previa consideración de oportunidad que solo el mediador determinará, sin oírlo. En efecto, podrá participar cuando a juicio particular del mediador sea necesario, recalcándose, "cuando su presencia sea estrictamente indispensable», pero no para los intereses del niño, sino que «para el desarrollo de la mediación». Sin embargo, bajo ningún punto de vista se vislumbra cómo el mediador podrá determinar esto, sin antes siquiera oír al niño — lo dicho por SANCHEZEZNARRIAGA cobra aplicación aquí-.

Pues bien, se aprecia con tal norma una falta de respeto a la autonomía progresiva del niño, toda vez que se decide por él, nunca pudiendo ejercer por sí mismo sus derechos, en este caso, su derecho a ser oído, por no tener siquiera la oportunidad de decidir autónomamente si ejercerlo o no.

Vemos aquí una seria contradicción en la norma, toda vez que pretendiendo por un lado resguardar el interés superior del niño, al mismo tiempo, por otro, lo transgrede. La disposición coarta de manera clara el legítimo derecho del niño a ejercer sus derecho de forma autónoma, lo cual en definitiva encierra una infracción categórica al principio del interés superior del niño, desde que — como señala Cillero y tuvimos oportunidad de expresar-imposibilita el legítimo ejercicio de sus derechos ${ }^{59}$. Se aprecia en definitiva que no

59 En este sentido Couso (2006), p. 148, expresa que en la Children’s Act inglesa, de 1989, el objeto es el bienestar del niño, el cual solo se obtiene si se considera sus deseos y sentimientos. Desde esta perspectiva, "si los procedimientos y prácticas concretas aseguran los deseos y sentimientos del niño ocuparán un rol central en la decisión, entonces esa ley protege derechos. En cambio, sin esa exigencia de atender a los deseos del niño, y sin asegurarles a estos centralidad en cada toma de decisión —mediante procedimientos 
hemos tomado en cuenta las prevenciones que nos hacía CONTRERAS ${ }^{60}$ mucho antes de la entrada en vigencia de la comentada Ley.

Bajo esta consideraciones, y siguiendo a Couso $^{61}$, se puede establecer que la norma es en exceso e injustificadamente paternalista ${ }^{62}$, pues coincidente a su vez con los postulados planteados por Garzón Valdés, no existe necesidad de instaurar una limitación tan severa y drástica al interés superior del niño. Como ya se expresó, el niño es plenamente capaz de ejercer sus derechos. La medida que plantea la norma de ninguna forma promueve o mejora, como acaba de verse, la autonomía del niño y la igualdad; por el contrario, la limita, en lo que vemos, una consagración de la arcaica consideración del niño como objeto de protección ${ }^{63}$.

y prácticas eficaces para ello-, una ley que defina el interés superior del niño como la máxima satisfacción de sus derechos no está protegiendo derechos ni está superando los problemas históricos del concepto "interés superior del niño".

60 Contreras (2002), expresa que "sería de inconmensurable interés escuchar la opinión de un niño o de un adolescente sobre estos tópicos, pero parecen estar destinados a ser 'víctimas' de nuestra 'adultocracia' ya que al tratar de protegerlos les estamos a veces imperceptiblemente restando derechos. Sin embargo, no debemos caer en la tentación de pensar que la salida sería una 'niñocracia', más bien esa idea nos devolvería al punto de partida. Todo análisis sobre el tema parece caer en la paradoja implícita con que titulo este artículo".

61 Couso (2006).

62 Ibíd. p. 147, establece que el principio del interés superior del niño no puede entenderse desde una concepción paternalista.

63 GARZÓn (1988) pp. 165 - 168, señala que en casos de incompetencia básica en un área determinada, para entender que un paternalismo jurídico, o sobreprotección jurídica, es necesario, se deben cumplir ciertas condiciones, a saber: que se trate de casos en que exista una incapacidad manifiesta, que el autor denomina incompetencia básica, para desempeñar cierta área —en este caso, para ejercer cierto derecho—, y además, que la medida que adopta el ordenamiento jurídico en todo caso será adecuada para mejorar condiciones de autonomía e igualdad. Expresa que si "Las dos condiciones mencionadas son necesarias y su conjunción las transforma en suficientes. El razonamiento justificante de una medida paternalista tiene pues que partir de dos premisas, una de tipo empírico (la verificación de una incompetencia básica) y otra de tipo ético normativo (el déficit provocado por una incompetencia básica debe ser superado, justamente en aras de la autonomía y la igualdad que quienes sostienen la vigencia exclusiva del principio de daño consideran que son puestas en peligro por el paternalismo jurídico)". De esta forma, Couso (2006) p. 152, citando a GARZÓN: "Si la medida no es empíricamente necesaria y adecuada para ello, a los perjuicios a los que se expuso el sujeto con una incompetencia 
Teniendo en cuenta la doctrina mencionada en el acápite anterior, no tiene porqué considerarse que con la participación de los niños en el proceso de mediación los padres verán minado su poder de decisión, y que además podría existir una afectación de la imparcialidad del mediador, toda vez que el mediador no es quien decide la solución al conflicto entre las partes, sino que otorga las bases y orientaciones para que sean ellas quienes logren encontrar la solución que sea la más óptima, benigna y eficaz, para la solución de la controversia. Desde este punto de vista, la participación de los niños en el proceso de mediación ayuda a vislumbrar caminos diversos en cuanto a la orientación de los padres en la toma de sus decisiones, quienes se verán informados de primera fuente de las consecuencias que sus decisiones puedan tener en el ámbito de afectación de los intereses de los niños que bajo su cuidado se encuentren. Lo anterior por tanto, a nuestro modo de ver, se constituye en una protección a los intereses de todos los integrantes del núcleo familiar, y principalmente los de niños y niñas.

Por otro lado, ya se ha señalado que la participación de los niños en un proceso de mediación es a todas luces menos estresante y perturbadora que la participación que hoy en día tienen en un proceso judicial propiamente tal. Con esto, necesario es recalcar que el derecho a ser oído se protegería de forma más eficiente si se dan las condiciones para que en el proceso de mediación el niño pueda participar de manera no estructurada, sino libremente, de acuerdo a sus aspiraciones e inquietudes. Esto que no es baladí impone a quien ejerce la actividad de mediador, la obligación de estar capacitado para la entrevista con niños y niñas ${ }^{64}$, ya sea en forma personal o con la colaboración de psicólogos u orientadores, de manera que en un contexto de tranquilidad y en orden de simetría, la participación de los niños, que no sería impuesta como en el caso de su participación en procesos judiciales, se realizaría de manera espontánea y sin transgresión de su faz psíquica. En este sentido, clarificadoras son las condiciones que establece el Comité para estimar la observancia del derecho del niño a ser escuchado en un proceso determinado, destacando, entre otras, la necesidad de ser transparente e informativo, voluntario, adaptado al niño, incluyentes, apoyado en la formación, responsable ${ }^{65}$.

básica, se suma un nuevo perjuicio: su autonomía actual está siendo sacrificada sin sentido".

64 Couso (2006) p. 153, expresa que "la "escucha" de estos contenidos no discursivos exige dar tiempo al niño y contar con una competencia especial por parte de quien consulta su 'opinión'".

65 Comité de los Derechos del Niño (2009) pp. 31 - 33. Clarificadoras condiciones establece él, para estimar la observancia del derecho a ser escuchado en un proceso determinado, 
A mayor abundamiento, ya Bustelo señala que las habilidades de un buen mediador deben ir relacionadas con "un buen conocimiento de su propio cuerpo, de sus percepciones y emociones, más un trabajo intenso en el lenguaje corporal, permitieron incluir esta mirada como actividad habitual,...". Agrega que "muchas de las cosas que no se dicen, se expresan con el cuerpo. Saber leerlas e interpretarlas para traducirlas en palabras o acciones es de gran utilidad para la agilización del trámite de la mediación" ${ }^{\prime \prime 6}$.

Finalmente, considerar que los padres son los únicos que saben lo que beneficia a los hijos, de forma patente retorna a la estimación que con la Declaración Universal de Derechos del Niño se había superado, esto es, la consideración implícita de que el menor no es sujeto de derecho; una consideración en que solo se le atribuye la calidad de objeto de protección, sin la posibilidad de poder ejercitar los derechos que le son propios a su calidad de niño. Tal argumentación atenta claramente con los derechos de los niños y niñas consagrados en la Declaración y con el principio del interés superior. En este sentido, si bien el artículo 5 de la Convención de Derechos del Niño declara que la autonomía del niño es progresiva en virtud de la evolución de sus facultades, posibilitando a los padres impartir orientaciones y dirección apropiada para que el niño ejerza los derechos reconocidos ${ }^{67}$, no los faculta de forma alguna a ejercerlos por él, y menos sin considerar su punto de vista u opinión.

Por otro lado, ¿ de qué otra forma los padres en situación de ruptura podrán darse cuenta de las intenciones y pretensiones más íntimas de sus hijos si no es con su participación directa? Los niños, por muy pequeños que sean en cuanto a su edad, siempre tienen percepción concreta de lo que sucede a su alrededor, y son capaces de manifestar de múltiples formas sus necesidades. De acuerdo a esto, atendido el mal entendimiento social de que la patria potestad va más allá del solo ejercicio de los poderes parentales sobre los bienes de los hijos, si los padres no se detienen a oírlos, creyéndose dueños de su voluntad, no podrán darse cuenta del real alcance de sus decisiones en el núcleo de la familia. Qué mejor opción que oír a los hijos en un proceso de mediación al que voluntariamente los padres se han sometido, el cual podría eventualmente traer consecuencias ventajosas, si se garantizan, además, requisitos mínimos de protección física y emocional de los niños, de forma que su participación no le sea perniciosa.

destacando, entre otras, ser transparentes e informativos, voluntarios, adaptados al niño, incluyentes, apoyados en la formación, responsables.

66 Bustelo (1995) p. 84.

67 Cillero (1990) p. 6. 
Esperamos que el Proyecto de Ley de Sistema de Garantías de los Derechos de la Niñez ingresado al Congreso mediante mensaje presidencial con fecha 24 de septiembre del presente año ${ }^{68}$ se haga cargo de manera efectiva de los reparos que a la legislación nacional actual ya se ha hecho tanto por la doctrina como por los organismos internacionales en torno a la consideración del niño como sujeto de derecho y en cuanto a la protección de su derecho a ser oído. Lo anterior no solo como declaración de principio, sino también mediante una intervención o cambio en los diversos procedimientos donde se discutan intereses de niños y niñas.

De acuerdo a ello, orientativo es terminar con algunos breves comentarios al mencionado Proyecto de Ley. El mismo es un acierto, consagra en forma específica el principio del interés superior del niño, entendiéndolo como el disfrute y satisfacción de sus derechos, así como el principio de autonomía progresiva y su derecho a ser oído.

Respecto de este último, destaca que en el artículo 19 inciso segundo se contemple que los órganos del Estado, en el ámbito de sus competencias, velarán para que en los procedimientos en que participe directamente un niño existan medios adecuados a su edad, sexo y madurez, con el objeto que éste pueda formarse un juicio propio y pueda expresarlo, no obstante establecer antes - en el inciso primero-, que el ejercicio de este derecho estará limitado —entendemos nosotros - a la consideración o evaluación del desarrollo de las facultades del niño $0^{69}$.

La redacción que plantea la disposición normativa en comento, entendemos, no es coincidente con los planteamientos que hiciéramos en torno a la posibilidad de que un niño pueda ejercer su derecho a ser oído en consideración a su madurez. En efecto, teniendo en cuenta lo reiteradamente fallado por la jurisprudencia de la Suprema Corte de la Provincia de Buenos Aires, en concordancia con los postulados de AlAEZ, indicábamos que los niños pueden ejercer su derecho a ser oídos aún sin siquiera ser necesaria una previa evaluación de madurez. En tal sentido, ya la Observación General № 12 del Comité especificaba en el año 2009 que "aunque se encuentren con dificultades para

Boletín No 10.315-18 de la Cámara de Diputados de Chile.

La norma en comento establece: "Derecho a ser oído. Todo niño tiene derecho a que sus opiniones sean oídas y debidamente consideradas, de acuerdo con el desarrollo de sus facultades, en los procedimientos o actuaciones en que se decida sobre alguna cuestión particular cuya determinación pudiere afectar sus derechos o intereses, especialmente en el ámbito familiar, escolar, sanitario, comunitario, administrativo y judicial". 
evaluar la edad y la madurez, los Estados partes deben considerar a los niños como un grupo que debe ser escuchado, por lo que el Comité recomienda enérgicamente que los Estados partes hagan el máximo esfuerzo por escuchar a los niños que se expresan colectivamente o recabar sus opiniones" ${ }^{70}$. Por su parte, orientativa es la redacción de los artículos $2^{71}$ y $24^{72}$ de la Ley argentina $N^{\circ} 26.061$, de 28 de septiembre de 2005, en los cuales se aprecia la posibilidad de que los niños puedan participar y expresar libremente su opinión, cualquiera sea la forma en que se manifiesten, en todos los ámbitos.

Ahora bien, debemos agregar que el término "madurez", al cual hace referencia la Observación General № 12 del Comité, tiene una connotación completamente distinta a los conceptos de "desarrollo de las facultades de un niño" que utiliza el Proyecto de Ley. Entendemos que este último hace referencia solo a un aspecto específico de la vida del niño, lo que podría tener como consecuencia una visión sesgada e incidir negativamente en la estimación que se tenga de su efectiva capacidad para ejercer el derecho a ser oído. En tal sentido, sería preferible que la norma usara el mismo término que la Observación General № 12 utiliza, tal como lo hace la Ley argentina 20.061 en su artículo 2 letra b), o bien, hacer alusión a uno acorde con la definición de madurez que el Comité especifica. En definitiva, uno que contemple la consideración del desarrollo afectivo, cognitivo y emocional del niño, en estrecha relación con el principio de autonomía progresiva.

Por otro lado, y a mayor abundamiento, la limitación que se plantea en la norma proyectada nos hace recalcar con énfasis la necesidad de que en los diversos procedimientos en que tengan intereses los niños se cumplan de manera estricta las condiciones que la Observación General № 12 del Comité de los Derechos del Niño efectúa para considerarlos respetuosos del derecho del niño a ser escuchado, los cuales, como apreciamos, no se mencionan de manera alguna en la disposición normativa en comento. Incluso, y por el contrario, a nuestro juicio se consagra claramente otra forma de limitación de este derecho del niño. A saber, el hecho de que los órganos del Estado deberán establecer mecanismos efectivos para el respeto del derecho del niño a ser oído "de

70 Comité de los Derechos del Niño (2009) p. 7.

71 La norma señala: "Las niñas, niños o adolescentes tienen derecho a ser oídos y atendidos cualquiera sea la forma en que se manifiesten, en todos los ámbitos. Los derechos y las garantías de los sujetos de esta ley son de orden público, irrenunciables, interdependientes, indivisibles e intransigibles".

72 La disposición establece: "Las niñas, niños y adolescentes tienen derecho a: a) Participar y expresar libremente su opinión en los asuntos que les conciernan y en aquellos que tengan interés $[\ldots]^{\prime \prime}$. 
acuerdo a sus disponibilidades presupuestarias", esto es, limitando el efectivo ejercicio del derecho a cuestiones netamente económicas. Ante esta inconsecuencia legislativa, que esperamos sea eliminada, basta solo recordar que la Observación General № 12 del Comité insta a los Estados parte a derribar las barreras que en el plano económico impiden el ejercicio efectivo del derecho de los niños a ser oídos, al señalar que "el objetivo de lograr oportunidades de aplicar verdaderamente el artículo 12 hace necesario desmantelar las barreras $[. .$.$] económicas, [. .$.$] que actualmente inhiben la oportunidad de que los$ niños sean escuchados y el acceso de los niños a la participación en todos los asuntos que los afecten"73. En efecto, el Comité ya en el año 2009 observaba que, en la mayoría de las sociedades del mundo, la observancia del derecho del niño a expresar su opinión sobre la amplia gama de cuestiones que lo afectan y a que esa opinión se tenga debidamente en cuenta seguía viéndose obstaculizada por muchas prácticas y actitudes inveteradas y por barreras políticas y económicas ${ }^{74}$. Y en el año 2002 recomendaba a Chile que definiera "[...]claramente sus prioridades en el ámbito de los derechos del niño a fin de garantizar que se asignen fondos "hasta el máximo de los recursos de que se disponga y, cuando sea necesario, dentro del marco de la cooperación internacional" para lograr el pleno ejercicio de los derechos económicos, sociales y culturales de los niños, $[\ldots]^{\prime 77}$. Estamos aún a tiempo de remediar esta situación.

Respecto de lo indicado inmediatamente antes, ilustrativo es el artículo 27 de la Ley argentina $N^{\circ} 20.061$, en el cual, a diferencia de lo que señala nuestra pretendida legislación, se establece sin ninguna limitación el deber del Estado de garantizar el derecho del niño "a) A ser oído ante la autoridad competente cada vez que así lo solicite la niña, niño o adolescente; b) A que su opinión sea tomada primordialmente en cuenta al momento de arribar a una decisión que lo afecte; [...] d) A participar activamente en todo el procedimiento; e) A recurrir ante el superior frente a cualquier decisión que lo afecte". Lo anterior además, es plenamente coincidente con el interés superior del niño que la misma legislación define como "la máxima satisfacción, integral y simultánea de los derechos y garantías" ${ }^{\prime \prime 7}$, reafirmándose con tal redacción su carácter de principio, el cual no puede encontrar más limitaciones que no sean aquellas vinculadas estrictamente con su esencia. Se aprecia, pues, otra diferencia con nuestra futura legislación, en la cual se define al interés

Comité de los Derechos del Niño (2009) p. 33.

Ibíd. p. 6.

Comité de los Derechos del Niño (2002) p. 4.

Ley n²0.061 de 2005, artículo 3. 
superior del niño, entendemos de manera muy pobre, solo como "el disfrute y satisfacción de sus derechos".

No cabe más que decir que si lo buscado por el Proyecto de Ley en comento es una protección real del derecho de los niños a ser oídos en todos los procesos que digan relación con sus intereses, es necesario que la consagración adecuada de este derecho sea además acompañada de importantes modificaciones a otros cuerpos normativos, de tal manera de hacer efectivo plenamente y sin limitaciones el derecho. En lo que nos convoca, una modificación necesaria sería al sistema legal de mediación nacional. Esperemos ello sea considerado en la tramitación legislativa.

\section{CONCLUSIONES}

1. Se debe tomar en el concepto de mediación familiar la estrecha relación que existe entre los objetivos de la misma, como fuente de acuerdo entre las partes en conflicto (los padres), y las consecuencias que tales acuerdos o acciones generarán en el entorno familiar, que de forma clara afecta considerablemente a los hijos. En este sentido, debido a la forma en que están configuradas las familias en la actualidad, es en los hijos -el otro componente del núcleo familiar-, en los que en la mayoría de los casos repercutirá de mayor o menor medida la decisión a la que arriben los padres.

Teniendo en cuenta lo anterior, desde la conceptualización de la mediación familiar, entender que no solamente el objetivo principal es el acuerdo entre las partes, sino aquel acuerdo que sea en la mayor medida de lo posible beneficioso y eficaz para todos los integrantes del núcleo familiar, es considerar efectivamente el interés superior del niño como lo que es: un principio que orienta la labor del mediador para fomentar la producción del acuerdo entre los padres, que permite entender que en el proceso de mediación el menor es el centro de atención, y que tiene primacía respecto de los intereses de los padres, toda vez que orienta el conocimiento y protección de los reales e íntimos intereses de los hijos.

2. Desde la óptica en que definimos la mediación familiar, la participación de los niños en el proceso mismo es esencial. Por una parte el proceso es un espacio menos traumático de lo que pudiere ser una sala de audiencias, una entrevista con el juez, una oficina de pericia; e incluso, contando con las condiciones necesarias de seguridad para la faz psíquica del niño, es un espacio favorable para su normal desenvolvimiento, desde donde surjan de forma espontánea sus inquietudes, anhelos y pretensiones. 
Por otro lado, la participación activa de los hijos en el proceso de mediación permitiría a los padres ponerse en el lugar del niño, y no desde sus experiencias como padres, permitiendo acomodar las decisiones que tomen a unos efectos que sean beneficiosos para él; o incluso, por qué no, evitar muchas veces el quiebre definitivo de la relación entre la pareja estable o el matrimonio en aquellos casos en que el punto de vista del niño determine un cambio de mentalidad en las posturas en principio cerradas o sesgadas de los padres.

3. Los argumentos en orden a establecer las desventajas o consecuencias negativas que tendría la participación de los niños en el proceso de mediación son visiones retrógradas de la niñez y adolescencia, y de la función que los niños cumplen en nuestra sociedad.

No en vano el refrán que señala que "los menores son el futuro del planeta", donde tomando en cuenta los derechos consagrados en la Declaración de Derechos del Niño, a los mismos se les reconoce participación en todo espacio en que sus intereses estén en juego, por su calidad de sujetos de derecho. Tal reconocimiento se constituye, a la luz del principio del interés superior y el derecho a ser oído, en un mandato a todo ente público o privado, para que en cada gestión o proceso en que existan consecuencias para un niño o adolescente, él mismo tenga las herramientas y espacios óptimos y adecuados que permitan su participación.

En este sentido, la mediación familiar como espacio óptimo en el cual los padres puedan solucionar el conflicto que les aqueja, debe contar con las condiciones para que la participación de los niños sea adecuada y efectiva, con mediadores capacitados y habilitados para desempeñar su labor, donde además existan garantías de resguardo de su seguridad psíquica. Todo ello de manera que los niños y niñas sientan y sepan que su participación es relevante, pero en nada les perjudicará afectiva, emocional o físicamente.

4. La edad mínima para que un niño o niña pueda participar en un proceso de mediación debe dejar de ser la regla general, pasándose a un panorama legislativo y entendimiento colectivo de que, siendo necesaria la participación de los niños en los procesos que son de su interés, y con mayor razón en la mediación familiar, la fijación de una edad mínima se constituye en una barrera para permitir el ejercicio de su derecho de participación y ser oído... en una vulneración de los derechos del menor. 
El entendimiento de que, no importando la edad de un niño, por el solo hecho de serlo, tiene el derecho a participar en los procesos de su interés, importa el respecto de sus derechos. ¿De qué otra forma sabremos si lo que nos quiera manifestar un niño puede tener relevancia capital para la solución del problema, o su determinación en un sentido más benigno y eficiente, si no permitimos de partida su participación? La necesidad de apelar a la madurez de los niños, en el entendido de que la misma no se adquiere al alcanzar una determinada edad, sino que dependerá de una serie de circunstancias y contextos diversos, nos permitirá sumar un paso más hacia el respeto efectivo de los derechos de los niños, y a construir una convivencia social en que, en aquellos casos en que exista ruptura de la pareja estable o matrimonial, las decisiones que se hayan tomado por los padres tengan el valor agregado de configurarse en la opción que en la mayor medida de lo posible sea la más benigna y efectiva para la vida de los padres, y en forma determinante, de los hijos.

5. Es preciso un cambio legislativo que contemple el proceso de mediación desde el punto de vista del modelo circular narrativo, dejando de lado la consideración lineal que se centra principalmente en los intereses de los padres. La regulación actual, tras más de diez años de vigencia, se presenta en exceso paternalista y aún no considera a los niños y niñas como sujetos de derecho. Por su parte, la legislación que se espera regule de manera integral los derechos de las niñas y niños, debe ser examinada y evaluada profundamente antes de su entrada en vigencia, a fin de contar con una normativa que de manera cierta y significativa otorgue un respeto y protección efectivo a los derechos de los niños, especialmente, en relación al interés superior y el derecho a ser oído.

\section{BIBLIOGRAFÍA CITADA}

Alaez Corral, Benito (2003): Minoría de edad y derechos fundamentales (Madrid, Editorial Tecnos).

Bustelo ElıçABe-UrRiol, Daniel J. (1995): La mediación familiar interdisciplinaria (Madrid, Ensayo).

Carvo López, Felisa-María (2008): «Los hijos menores ante el proceso de mediación». Gómez Gállıgo, Javier (coordinador), Homenaje al Profesor Manuel Cuadrado Iglesias (Tomo I, España, Editorial Aranzadi S.A.).

Cillero Bruñol, Miguel (1990): "Infancia, Autonomía y Derechos: una Cuestión de Principios". Instituto Interamericano del Niño, la Niña y 
Adolescentes (IIN), pp. 1 - 15, disponible en: <http://www.iin.oea.org/ Infancia_autonomia_derechos.pdf >.

Cillero Bruñol, Miguel (1999): "El interés superior del niño en el marco de la Convención Internacional sobre los Derechos del Niño". Justicia y Derechos del Niño, Unicef, primera edición, Santiago, 1999, pp. 125 142, disponible en: <http://www.unicef.org/argentina/spanish/Justcia_y_ derechos_9.pdf >.

Comité sobre los Derechos del Niño (2002): Examen de los Informes presentados por los Estados Partes con arreglo al artículo 44 de la Convención. Observaciones finales del Comité sobre los Derechos del Niño: Chile. Naciones Unidas, de fecha 03 de abril de 2002.

Contreras Saronic, Oscar (2002): "Los niños en mediación familiar ¿objetos de protección o sujetos de derecho?", Terapias y Familia (año 10, n 16 , diciembre).

Couso, Jaime (2006): "El niño como sujeto de derechos y la nueva justicia de familia. Interés superior del niño, autonomía progresiva y derecho a ser oído", Derechos del Niño (№ 3 - 4, octubre): pp. 145 - 166.

Díaz Cappa, José, Fiscal de la Fiscalía de Illes Balears. Mediación con menores. Límites Jurídicos para su aplicación, Ponencia.

Figueredo, Ana Del Carmen (sin fecha): Derecho del niño a ser oído y participar en los procesos judiciales. Publicaciones jurídicas online del Poder Judicial de la Provincia de Corrientes, disponible en: < http://www.juscorrientes.gov.ar/publicacionesjuridicasbiblioteca/publicaciones/\#prettyPh oto/30/>.

García García, Lucía (2003): Mediación familiar. Prevención y alternativas al litigio en los conflictos familiares. I. Persona y familia (Madrid, Editorial Dykinson).

García Villaluenga, L. (2006): Mediación en conflictos familiares (Madrid, Editorial Reus).

Garzón Valdés, Ernesto (1988): ¿Es éticamente justificable el paternalismo jurídico? Biblioteca Virtual Miguel de Cervantes. Edición digital a partir de Doxa: Cuadernos de Filosofía del Derecho ( $\left.N^{0} 5,1988\right)$ : pp 155 - 173, disponible en: <http://www.cervantesvirtual.com/obra/ es-ticamente-justificable-elpaternalismo-jurdico-0/>. 
HAYNeS, John M. (1995): Fundamentos de la mediación familiar (Madrid, Editorial Gaia).

MOORE, Christopher (1995): El proceso de mediación (Barcelona, Editorial Granica).

Munuera Gómez, Pilar (2007): «El modelo circular narrativo de Sara Cobb y sus técnicas». Portularia, Universidad de Huelva (vol. VII, No 1 - 2): pp. $85-106$.

Papalia, Diane E. y Wendoos Olds, Sally (1978): Sicología del desarrollo: de la infancia a la adolescencia (Madrid, Editorial McWraw Hill).

Parkinson, Lisa (2005): Mediación Familiar. Teoría y Prácticas: Principios y estrategias operativas (España, Editorial Gedisa).

Rouız, Miguel (1989): "La familia, desde la teoría de la comunicación de palo alto". Reis: Revista Española de Investigaciones Sociológicas ( $N^{\circ} 48$, octubre - diciembre): pp. 117 - 136.

SÁnchez-EznarRIAGA, Luis Zarraluqui (2011): "El menor en los procesos de familia", Alcón Yusta, María Fuencisla y Federico, De Montalvo (coordinadores), Los menores en el proceso judicial (Madrid, Editorial Tecnos).

Stella Álvarez, Galdys. La visión del conflicto y su resolución en el nuevo perfil del abogado. Fundación Libra, disponible en: <http://www.fundacionlibra.org.ar/index.htm>.

SUARES, Marinés (2008): "El modelo circular narrativo en Mediación Familiar", Proyecto Hombre. Revista de la Asociación Proyecto Hombre ( $\left.\mathrm{N}^{\circ} 66\right)$ : pp. $45-49$.

SuAres, Marinés (2003). Mediando en Sistemas Familiares (Editorial Paídos).

Torres Escámez, S. (2000): "La mediación como medio de solución de conflictos jurídicos. La necesidad de su urgente regulación". Actualidad Jurídica Aranzadi (diciembre).

Universidad de Alicante, Licenciatura en Criminología, Asignatura: Psicología Criminal, El menor como testigo, disponible en: <http://rua.ua.es/dspace/bitstream/10045/3752/45/TEMA\%209\%20Psicolog\%C3\%ADa\%20 criminal.pdf>. 
Valero Matas, Jesús A. (2010): "La inclusión de los niños en el proceso de mediación familiar: reflexiones desde el caso neozelandés", Revista de Investigaciones Políticas y Sociológicas. Universidad de Santiago de Compostela (España, volumen 9, número 1): pp. 89 -100.

Vargas Pavez, Macarena (2002): "Los niños en la mediación familiar", Revista de Derechos del Niño (Chile, № 1, Año).

Vargas Pavez, Macarena (2008): "Mediación obligatoria. Algunas razones para justificar su incorporación", Revista de Derecho, Universidad Austral de Chile (Vol. XXI, No 2, diciembre).

Vargas Pavez, Macarena, Correa Camus, Paula (2011): "La voz de los niños en la justicia de familia de Chile", Revista lus et Praxis. Universidad de Talca (Año 17, No 1): pp. 177 - 203.

Vargas Pavez, Macarena, Correa Camus, Paula, Barros, Paula y Cerda, Andrea (2010): Informe Final Estudio "Niños, niñas y adolescentes en los tribunales de familia", Universidad Diego Portales (enero).

Villagrasa Alcaide, Carlos (2011): "Nuevas aplicaciones del procedimiento de mediación familiar en el libro segundo del Código Civil de Cataluña", Pérez Daudí, Vicente (coordinador), El proceso de familia en el Código Civil de Cataluña (Barcelona, Editorial Atelier).

\section{NORMAS JURÍDICAS CITADAS}

Convención sobre los Derechos del Niño, adoptada por la Asamblea General de las Naciones Unidas el 20 de noviembre de 1989.

Ley n ${ }^{\circ}$ 15/2009, del 22 de julio, de mediación en el ámbito del derecho privado. Boletín Oficial del Estado, 17 de agosto 2009.

Ley $n^{\circ} 26.061$, del 28 de septiembre de 2005, de Protección Integral de los Derechos de niñas, Niños y Adolescentes.

Ley $\mathrm{n}^{\circ} 19.968$ Crea los Tribunales de Familia. Diario Oficial, 24 de agosto 2004.

Ley Orgánica n 1/1996, de 15 de enero, de protección jurídica del menor, de modificación del Código Civil y de la Ley de Enjuiciamiento Civil. Boletín Oficial del Estado, 17 de enero de 1996. 
Mensaje Presidencial no 950-363: Proyecto de Ley de Sistema de Garantías de los Derechos de la Niñez. 21 de septiembre de 2015. Boletín № 10.315-18 de la Cámara de Diputados de Chile.

Observación General n ${ }^{\circ} 12$ del Comité de los Derechos del Niño. «El derecho del niño a ser escuchado». Naciones Unidas, 20 de julio de 2009.

Real Decreto de 24 de julio de 1889 por el que se publica el Código Civil. Boletín Oficial del Estado, 25 de junio de 1889.

\section{JURISPRUDENCIA CITADA}

STC 163/2009, de 29 de junio. 
